\title{
INTERSETORIALIDADE NAS POLÍTICAS PÚBLICAS DE ESPORTE E LAZER NO MUNICÍPIO DE ILHÉUS-BA
}

\author{
Dirceu Santos Silva, Universidade Estadual de Campinas - UNICAMP, Campinas, São \\ Paulo - Brasil \\ Marcel Ivan dos Santos, Universidade Federal do Espírito Santo - UFES, Vitória, Espírito \\ Santo - Brasil \\ Marco Aurélio Avila, Universidade Estadual de Santa Cruz - UESC, Ilhéus, Bahia - \\ Brasil
}

\section{RESUMO}

O artigo buscou discutir os processos de gestão pública e planejamento do esporte e do lazer no município de Ilhéus-BA, com foco na intersetorialidade. Trata-se de uma pesquisa descritiva, com abordagem qualitativa, que foi efetivada em duas etapas: análise documental; e entrevistas semiestruturadas com gestores do poder público municipal. Para tabulação dos dados, a técnica utilizada foi à análise de conteúdo. Os resultados evidenciam que as políticas públicas implementadas apresentam incipientes articulações intersetoriais no processo de planejamento e as ações não estão alinhadas às novas formas de gestão pública.

Palavras-Chave: Planejamento; Política; Intersetorialidade.

\section{INTERSECTORIALIDAD EN LAS POLÍTICAS PÚBLICAS DE DEPORTE Y OCIO EN EL MUNICIPIO DE ILHÉUS-BA}

\section{RESUMEN}

El artículo ha buscado discutir los procesos de la gestión pública y la planificación del deporte y el ocio en la ciudad de Ilhéus-BA, con orientación en la intersectorialidad. Se trata de un estudio descriptivo, con enfoque cualitativo, que se llevó a cabo en dos etapas: revisión bibliográfica; análisis de documentos; y entrevistas semiestructuradas con los gestores del poder público municipal. Para tabular los datos, la técnica utilizada fue el análisis de contenido. Los resultados muestran que las políticas públicas implementadas presentan incipientes articulaciones intersectoriales en el proceso de planificación y las acciones no son alineadas a las nuevas formas de gestión pública.

Palabras-Clave: Planificación; Política; Intersectorialidad. 


\title{
INTERSECTIRAL IN PUBLIC POLICY OF THE SPORT AND LEISURE IN THE TOWN OF ILHÉUS-BA
}

\begin{abstract}
The article discusses the processes of public management and planning of sport and leisure in the town of Ilhéus-BA, focusing on intersectoral. This is a research descriptive, with qualitative approach, which was carried out in two phases: document analysis, and semistructured interviews with managers of municipal government. To tabulate the data, the technique used was content analysis. The results show that the public policies implemented tentative incipient intersectoral planning process and actions are not aligned to new forms of public management.
\end{abstract}

Key-Words: Planning; Policy; Intersectoral. 


\section{INTRODUÇÃO}

As discussões sobre as políticas públicas de esporte e lazer no Brasil foram intensificadas com a criação do Ministério do Esporte no ano de 2003. Destacam-se dois projetos que têm sido implementados em diversos municípios: o Programa Esporte e Lazer da Cidade (PELC) e o Programa Segundo Tempo (PST). Esses programas, de acordo com Castellani Filho, ${ }^{1}$ rompem com o modelo hegemônico de desenvolvimento apenas do esporte de rendimento, dando ênfase às práticas de lazer. A partir desse período, o debate ficou em evidência no meio acadêmico e nos três âmbitos de governo: municipal, estadual e federal, sobretudo no que se referem às novas formas de planejamento político.

As novas formas de gestão pública, que tem raízes na década de 1980, recomendam ações democráticas, além de um planejamento integrado. Destacam-se dois modelos de gestão pública postos em prática, no Brasil, a partir da década de 1990: o primeiro foi o gerencial, que ganhou destaque a partir de 1994, quando o governo federal realizou uma reforma administrativa, por meio do Ministério da Administração Federal e Reforma do Estado (MARE), se aproximando das estratégias neoliberais com foco no mercado, desenvolvimento econômico e alinhamento com os organismos multilaterais internacionais; e o segundo foi o societal, que ganhou força no Brasil a partir do ano de 2003, com foco na dimensão política, cidadania e luta por direitos sociais. A participação da sociedade civil passou a ser compreendida como elemento importante para tornar a gestão mais democrática. ${ }^{2}$

Os dois modelos de gestão são compreendidos como os novos arranjos institucionais, que buscam a articulação entre os diferentes atores sociais em prol do aperfeiçoamento da gestão pública. Os modelos citados vão ao encontro do objeto de estudo, a partir do momento que existe uma proposta de tentativa de compreensão da gestão nos campos do esporte e do lazer no município de Ilhéus-BA, na tentativa de investigarmos se a gestão é democrática e se está de acordo com os novos modelos.

Na presente pesquisa realizamos um recorte da gestão municipal de Ilhéus, entre 2001 e 2008, período este marcado por duas gestões, com dois partidos distintos. Desse modo, a reflexão central do estudo girou em torno das seguintes questões: como se articulam e são planejadas as políticas de Ilhéus-BA, em relação aos setores do esporte e do lazer? Quais identificações de intersetorialidade podem ser encontradas na gestão pública municipal? 
A pesquisa pode justificada a partir do momento que assumem dimensões e significados de fenômenos únicos que não foram considerados problemas sociais "sérios" na sociologia. Esse tipo de pesquisa foi entendida como uma atividade vulgar orientada para o prazer, que ainda hoje sofrem certas restrições ou resistências como objeto de estudo científico e de relevância no universo acadêmico. ${ }^{3-4}$

O objetivo do artigo é identificar e discutir o planejamento da gestão pública do esporte e do lazer no município de Ilhéus-BA, bem como analisar a intersetorialdiade das ações políticas.

\section{MÉTODO}

Trata-se de uma pesquisa descritivo-analítica com abordagem qualitativa, realizada no município de Ilhéus-BA. O estudo foi efetivado em duas etapas: a primeira etapa constituiu-se de uma análise documental nos organogramas das instituições, Lei Orgânica Municipal, Relatório de Gestão 2001-2004, Projeto Jogos Escolares, Projeto Liga de Esporte, Projeto Verão Ilhéus Fitness, e Projeto Esportes para todos; na segunda etapa foram realizadas entrevistas semiestruturadas com (2) dois gestores públicos municipais que participaram dos planejamentos nos períodos de 2001 a 2008. O período foi justificado a partir do momento que permite a análise das continuidades e rupturas, uma vez que as duas gestões analisadas tiveram partidos políticos distintos no poder.

Os gestores entrevistados foram representados pela sigla G. O G1 foi o secretário da primeira gestão da Semec e o G2 foi o secretário da segunda gestão. Para os procedimentos de coletas de dados, em um primeiro momento foi apresentada a carta de intenção da pesquisa. Vale ressaltar que durante a segunda gestão ocorreu à cassação do prefeito Valderico Reis no ano de 2007, sendo substituído pelo vice-prefeito Newton Lima, o que gerou uma descontinuidade na gestão e um esvaziamento dos documentos das secretarias. Finalizou-se a coleta documental com a análise da Lei Orgânica do Município de Ilhéus por meio do website da Câmara Municipal. ${ }^{5}$

A categorização dos dados foi realizada por meio da análise de conteúdo, que permitiu um recorte dos textos de acordo com os conteúdos mais significativos para o estudo, para o posterior agrupamento e categorização das unidades de respostas. ${ }^{6}$ Para uma discussão mais consistente dos dados coletados foi utilizado um referencial teórico amplo, que 
envolveu a conceituação de política pública, planejamento, gestão pública e intersetorialidade. Posteriormente foram discutidas as políticas públicas de esporte e lazer no município de Ilhéus, bem como a gestão pública, com foco na intersetorialidade das ações.

\section{PLANEJAMENTO E POLÍTICAS PÚBLICAS}

A concepção de política ao longo da história passou por constantes modificações e avanços, se tornando um termo complexo e polissêmico. A política englobou tudo que diz respeito à vida coletiva das pessoas em sociedade e em suas organizações; compreendeu um conjunto de processos, métodos e expedientes usados por indivíduos ou grupos para manutenção do poder; e associou à arte de governar e realizar o bem público, que considera o processo de destruição da natureza como o não "bem público".

À medida que houve evolução do conceito de política, o termo se aproximou do conhecimento ligado ao controle da vida humana em sociedade, sendo organizado por meio de leis e por jurisdições político-administrativas dos municípios, estados e nações. Após esta evolução, o Estado passou a realizar intervenção na economia e se aproximou do conceito de políticas públicas. ${ }^{7}$

De acordo com Di Giovanni ${ }^{8}$ a política pública vai além da intervenção do Estado numa situação social considerada problemática. Toda política pública se baseia numa "teoria", um conjunto de asserções de origem diversa (racional ou não), que dá sustentação às práticas de intervenção, em busca de um determinado resultado. Existem quatro estruturas elementares nas políticas públicas: formal, composta por teorias, práticas e resultados; substantiva, composta por atores, interesses e regras; material, composta pelo financiamento, suportes, e custos; e simbólica, quando composta pelos valores, saberes e linguagens.

Nas políticas públicas o planejamento existe de diversas formas, com características e especificidades que variam de acordo com a localidade, a região ou o país. No Brasil, os problemas do planejamento estão relacionados à ênfase dada ao tecnicismo, à burocracia e as previsões dos economistas. A concepção de planejamento envolve a tomada de decisão, sendo uma construção política e social que vai além do produto técnico dominado por economicistas e burocratas. ${ }^{9}$ 
O planejamento se refere a "um processo de decisão político-social que depende de informações precisas, transparência, ética, que sejam aceitáveis para toda a sociedade". Os processos de tomada de decisão envolvem reuniões e discussões com a sociedade, levantamento de modelos matemáticos com mapas detalhados, criação de legislação própria, distribuição de responsabilidades e poderes, além da geração de um plano no final do processo. ${ }^{9}$

As propostas de planejamento que valorizavam os mecanismos de descentralização e de participação da comunidade surgiram no final dos anos 1980. O modelo de planejamento centralizado cedeu espaço para novas formas de gestão, que preveem maior articulação com o mercado e a sociedade civil. Esses novos arranjos institucionais que superam o modelo de provisão estatal e o modelo centralizado apresentam potencial para fortalecimento de ações coletivas e socioeducativas, além da formação de redes institucionais, articulações intersetoriais, articulações intergovernamentais e envolvimento da sociedade civil. ${ }^{10}$

De acordo com Farah $^{10}$ a integração nos processos de planejamento envolve a relação entre o Estado e o mercado, e expõe as novas formas de articulação: a) a articulação intergovernamental vertical, que ocorre entre as instâncias federal, estadual e municipal; b) a articulação horizontal, que ocorre entre as instituições públicas de uma mesma instância; e c) a articulação intersetorial, que indica a constituição de um processo de elaboração e implementação de políticas públicas descentralizadas. Essas articulações evidenciam a valorização de novas práticas de gestão pública com a inserção de novos participantes nos processos de planejamento. Os governos locais passam a exercer um papel de coordenação, mobilizando as ações dos diferentes atores sociais no processo de gestão.

\section{Novas formas de Gestão Pública: foco nas ações intersetoriais}

Gestão corresponde à ação de administrar, de dirigir e de gerir a vida, os destinos, as capacidades das pessoas e os próprios bens que lhes pertencem. Logo, quem gere alguma ação ou instituição deve buscar resultados nos setores sociais, culturais e econômicos. ${ }^{11}$

Tenório $^{12: 16}$ afirma existir dois modelos de gestão: a primeira se refere a gestão estratégica, que corresponde a "[...] um tipo de ação social utilitarista, fundada no cálculo de meios e fins e implementada através da interação de duas ou mais pessoas, na qual uma delas tem autoridade formal sobre a(s) outra(s)"; e a segunda corresponde a gestão social, que está Conexões: revista da Faculdade de Educação Física da UNICAMP, Campinas, v. 11, n. 3, p. 13-35, jul./set. 2013. 
atrelada a identificar as políticas públicas como uma possibilidade de gestão democrática, pela qual é buscado o cidadão deliberativo que participa do processo e não apenas o eleitor e/ou contribuinte categórico que não participa da implementação de ações políticas nos municípios. ${ }^{12}$ A gestão social contrapõe-se à gestão estratégica à medida que propõe "um gerenciamento mais participativo, dialógico, no qual o processo decisório é exercido por meio de diferentes sujeitos sociais". 13:16

No Brasil, destacaram dois modelos distintos de gestão pública, um mais gerencial e outro mais societal, que se caracterizam como as novas formas de gestão, cujo objetivo é romper com o paradigma centralizado das ações políticas. O primeiro modelo corresponde ao gerencial, que teve início nos anos de 1980 com base nos modelos inglês e estadunidense. $\mathrm{O}$ projeto político tem como escopo o alinhamento às recomendações dos organismos multilaterais internacionais com foco nas dimensões econômico-financeira e institucionaladministrativa. O modelo gerencial se caracteriza por ser participativo no discurso e centralizador nas decisões. No Brasil, a gestão mais próxima desta vertente ocorreu no governo de Fernando Henrique Cardoso (1995-2002), quando foi implementada uma gestão com características neoliberais, enfatizando a privatização e focalização com foco no mercado. O segundo se caracteriza como o modelo de gestão societal, que tem raízes nos movimentos sociais brasileiros nos anos de 1960. O projeto político enfatiza a participação social e tem como base a dimensão sociopolítica. Este modelo incentiva às iniciativas locais, com elaboração de experiências da gestão com foco no cidadão. No Brasil, o governo que mais se aproximou desta vertente foi o de Luís Inácio Lula da Silva (2003-2006), quando criou mecanismos de participação e permitiu a aproximação entre a sociedade civil. ${ }^{1}$

As políticas devem levar em consideração uma visão de totalidade em prol da qualidade, possibilitando o fortalecimento de ações intersetoriais de cunho coletivo. A intersetorialidade se refere a uma forma de articulação de experiências ao longo do desenvolvimento do planejamento, implementação e avaliação das ações, em prol do desenvolvimento social e inclusão social. ${ }^{14} \mathrm{~A}$ intersetorialidade tem um conceito próximo de descentralização, à medida que compreende a transferência do poder de decisão na política e participação da sociedade civil, ou seja, a descentralização viabiliza a intersetorialidade para promover a inclusão social. ${ }^{15}$ 


\section{Políticas Públicas de Esporte e Lazer}

O lazer foi assegurado como direito social na Constituição Federal Brasileira de 1988, ao estabelecer no seu Art. 6": "São direitos sociais a educação, a saúde, o trabalho, a moradia, o lazer, a segurança, a previdência social, a proteção à maternidade e à infância, a assistência aos desamparados, na forma desta Constituição". E o esporte só foi complementado no Art. 217, ao assegurar que é dever do Estado fomentar práticas desportivas. $^{16}$

Após o reconhecimento como direito social em 1988, ocorreu um processo inverso, tendendo a aproximação com as estratégias neoliberais, que ganhou destaque no Brasil a partir de 1989, dificultando assim, a sua implementação como ação do Estado. Só em 2003 o lazer foi incluído como programa em âmbito federal, logo após a criação do Ministério do Esporte, com a implementação do PELC. Além dessa inclusão de um programa específico para tratar o lazer, foi destaque a realização da I Conferência Nacional do Esporte (CNE) no ano de 2004, a II CNE em 2006 e a III CNE em 2010, que realizaram um debate sobre a temática.

A relação entre o esporte e o lazer ficou ainda mais próxima com a realização da I CNE, realizada em 2004, cujo documento final estabeleceu uma "Política Nacional do Esporte e do Lazer" e reafirmou a constitucionalização dos setores de esporte e lazer como "[...] direitos sociais e, por isso, interessam à sociedade, devendo ser tratados como questões de Estado, ao qual cabe promover sua democratização, colaborando para construção da cidadania”. No ano de 2006 foi realizada a II CNE, que objetivou a consolidação do apoio e financiamento das políticas públicas descentralizadas, com foco nos problemas sociais e adversidade regional. ${ }^{17-18}$

No entanto, tanto na I CNE, quanto na II CNE foi perceptível um descompasso entre as demandas discutidas nas "Conferências" e o que foi implementado pelo Ministério do Esporte. Na I e na II CNE não foi construído um modelo social e político que reconheça o esporte e o lazer como direitos sociais, apenas um discurso falacioso que entende os campos como funcionais e remediadores de problemas sociais. As "Conferências" se configuraram como uma forma de descentralização das discussões acerca das políticas 
públicas, no entanto, na prática ocorreu a centralização na tomada de decisões nos âmbitos municipal, estadual e federal. ${ }^{19}$

Na III CNE foi elaborado o Plano Decenal do Esporte, com o objetivo de tornar o país uma potência esportiva mundial, cujo tema central foi "Por um time chamado Brasil", já que o país sediará os a Copa do Mundo de 2014 e os Jogos Olímpicos de 2016.

Para entendermos as políticas públicas de esporte e lazer no Brasil, via Ministério do Esporte é imprescindível discutir os conceitos de cada setor. Numa primeira discussão, merece destaque a conceituação mais utilizada do lazer ao longo desse processo, a qual foi proposta por Dumazedier ${ }^{20: 34}$ ao considerar o mesmo como um:

[...] conjunto de ocupações às quais o indivíduo pode entregar-se de livre vontade, seja para repousar, seja para divertir-se e para entreter-se ou, ainda para desenvolver sua informação ou formação desinteressada, sua participação social voluntária ou sua livre capacidade criadora após livrar-se ou desembaraçar-se das obrigações profissionais, familiares e sociais.

Dumazedier ${ }^{20}$ propõe no seu conceito as três esferas que o mesmo classifica como os 3 D's que integram o lazer, o descanso, o divertimento e o desenvolvimento social e pessoal. Com o avançar das pesquisas no campo do lazer, percebeu-se como é complexo a palavra e os múltiplos significados que existem relacionados à sua definição na sociedade, o que fez gerar um debate acerca dos novos conceitos.

Dentre os conceitos mais utilizados no Brasil, se encontra o proposto por Marcellino, ${ }^{21}$ ao entender o lazer a partir das diversas influências da vida social, sendo apontado como um espaço para socialização e não mais apenas para descontração e gasto do tempo livre. Envolve dois fundamentos importantes: tempo e atitude. $\mathrm{O}$ primeiro está relacionado ao tempo liberado do trabalho ou "tempo livre", além da liberdade das questões sociais, como família e religião. Enquanto que a atitude é caracterizada com o tipo de relação que se verifica entre o sujeito e a experiência.

Em uma concepção ampliada, o lazer é compreendido como um conjunto do comportamento humano, como meio para desenvolver a vida pessoal e coletiva. O lazer pode ser compreendido como espaço-tempo liberado, condição situacional para autogerir o seu sentido, não sendo importante buscar uma definição precisa. É um conceito 
contemporâneo, que envolve intencionalidades paralelas ou combinadas, até mesmo opostas e contraditórias. $^{22}$

O esporte pode ser caracterizado em três dimensões: o esporte participativo, o qual se caracteriza por práticas de formas voluntárias, que buscam a integração dos indivíduos e plenitude da vida social, podendo ser voltada para promoção da saúde, lazer, educação e preservação do meio ambiente; o esporte educacional, que se refere à prática no âmbito dos sistemas de ensino, sem seletividade e exclusão, em busca do desenvolvimento integral dos indivíduos e formação do mesmo para exercer sua prática cidadã e de lazer; e por fím temos o esporte de rendimento, caracterizado por regras nacionais e internacionais, com o escopo de obter resultados, que tem como foco a integração dos países e comunidades. ${ }^{23}$

Bracht $^{24}$ propõe de forma diferente as dimensões do esporte, ao destacar apenas o esporte de rendimento e o esporte como prática de lazer, argumentando que os dois tipos de esporte tem potencial educativo. A compreensão ampla dos conceitos de esporte e de lazer é imprescindível para se pensar em uma política intersetorial, e a sua discussão foi de grande relevância para compreensão da gestão pública da Semec em Ilhéus.

No que diz respeito às discussões sobre as políticas públicas de esporte e lazer na perspectiva da intersetorialidade é relevante destacar que esse tipo de ação política se configura como um fator de viabilização do desenvolvimento e da inclusão social enquanto ação do Estado. De acordo com Bonalume, ${ }^{25: 5-6}$

[...] A intersetorialidade não é um conceito em si autoexplicativo, o mesmo enunciado pode referir-se a objetivos e posturas metodológicas muito diversas, o que demanda que na sua utilização se explicite os pressupostos, estratégias e meios para que uma política se efetive como tal. Ela é um princípio que privilegia a integração matricial das políticas sociais tanto na fase de planejamento quanto nas de execução e monitoramento. Essa matricialidade representa o eixo coordenador e organizador dessas políticas, potencializando sua integração, com impacto positivo em seus efeitos.

A intersetorialidade se configura como a articulação de saberes e experiências no planejamento, execução e avaliação de ações, visando o desenvolvimento da sociedade e inclusão social. A tentativa é reverter o quadro de exclusão social, promover melhorias na qualidade de vida da população e superar a fragmentação das políticas. ${ }^{14-15}$ 
A conceituação de intersetorialidade é aperfeiçoada a partir do momento que "incorpora a ideia de integração, de território, de equidade, enfim, de direitos sociais". ${ }^{26: 27}$ As políticas intersetoriais são entendidas como possibilidades para otimização dos recursos escassos para resolução de problemas, que dependem de um processo de aprendizagem. O conceito de intersetorialidade se aproxima do que expõe Junqueira ${ }^{15}$, ao dizer que este tem como objetivo principal o desenvolvimento social por meio da articulação de saberes entre os cidadãos, instituições públicas e privadas num processo de cogestão. Nos setores do esporte e lazer, a intersetorialidade se apresenta de forma superficial e a aplicação deste mecanismo depende de um processo de aprendizagem, que demanda tempo.

De acordo com Bolanume ${ }^{27}$ as ações integradas favorecem a compreensão do esporte e do lazer enquanto direitos sociais, como dimensões da cultura, com grande potencial de relação com diversas áreas de conhecimento e de ação. Para a efetivação dessas políticas é preciso considerar: o perfil multidisciplinar dos sujeitos envolvidos; a diversidade e pluralidade dos interesses culturais do lazer; a crescente preocupação e valorização com a utilização do tempo livre, para além da simples ocupação; a capacidade de mobilização e organização das pessoas; o entendimento atual de que intersetorialidade deixa de ser uma proposta de gestão e passa a ser um requisito essencial na formulação de políticas públicas.

\section{Esporte e lazer: ações intersetoriais a partir da Semec em Ilhéus}

No município de Ilhéus a instituição responsável pelo esporte e lazer tem sido a Semec. Segundo relatório da primeira gestão da instituição (2001-2004) o esporte foi compreendido pelo município como direito social. O escopo da Semec é garantir o acesso da cultura corporal e da assistência a toda comunidade, bem como na qualidade de vida a todos os habitantes do município. ${ }^{28}$

O organograma da Semec foi organizado da seguinte forma: 01 Secretário de Esportes e Cidadania, 01 Chefe de Setor de Estudo e Planejamento Esportivo, 01 Chefe de Setor de Esporte e Lazer, 01 Chefe de Sessão da Administração de Ginásio de Esporte e Quadras Esportivas e 01 Chefe de Sessão da Administração do Estádio Mário Pessoa. ${ }^{29}$

O Município de Ilhéus dispõe dos seguintes equipamentos que são utilizados para execução de eventos e projetos: 01 Estádio Municipal (Mário Pessoa); 01 Ginásio de Esportes (Herval Soledade); Quadras poliesportivas em Escolas e Associações; Quadras 
poliesportivas em Bairros; Clubes e Associações, como o Clube Social de Ilhéus, a AABB (Associação Atlética do Banco do Brasil); além dos espaços da Universidade Estadual de Santa Cruz (UESC), Centro de Convenções de Ilhéus, dentre outros. Estes espaços ainda são insuficientes para o desenvolvimento de atividades, projetos e práticas para o acesso democrático ao lazer e ao esporte, pois ainda faltam arenas esportivas, recursos humanos, políticas públicas voltadas para o setor e infraestrutura básica para realização destas atividades.

A Lei Orgânica do Município de Ilhéus contempla o esporte no Art. 240, ao garantir por intermédio da Semec e em consonância com outras instituições esportivas, a promoção, o estímulo, a orientação e o apoio à prática do desporto formal e informal, com proteção e incentivo às manifestações esportivas de criação baiana e de âmbito nacional. No Art. 244 ainda foi contemplada à criação do "Conselho Municipal de Desporto, regulamentado através de lei complementar". No entanto, não foi verificada a criação do Conselho Municipal de Esporte até o ano de 2009, quando foi finalizada a coleta de dados da pesquisa. $^{5}$

Na esfera do lazer, o Art. 242, assegura que o município reservará áreas destinadas ao lazer ativo como forma de bem-estar e promoção social, saúde, higiene e educação de todas as faixas etárias e sociais da população, incentivando e reconhecendo a mesma como forma de promoção social. O lazer foi compreendido em Lei Orgânica do Município como um caminho para chegar a outros direitos como a saúde e a educação ${ }^{5}$ Santos e Amaral $^{30}$ afirmaram que o lazer continua hierarquizado e subordinado aos outros direitos, não tendo fim si mesmo e não se legitimando de fato como um direito social.

Os prefeitos que estiveram administrando a cidade no período estudado foram: Jabes Ribeiro (2001-2004) na primeira gestão; e Valderico Reis (2005-2007) e Newton Lima (2007-2008) na segunda gestão. A mudança na segunda gestão deu-se com a caçassão do prefeito Valderico Reis, assumindo em seu o lugar o vice-prefeito Newton Lima. Acrescentamos, para fins de esclarecimento, que na primeira visita realizada à Semec, com intuito de entregar a carta de apresentação da pesquisa, o Chefe de Setor de Estudo e Planejamento Esportivo fez um relato que chamou nossa atenção. Segundo o gestor, após a cassação do prefeito, a Secretaria foi esvaziada, levaram $H D$ do computador, projetos e 
todos os documentos da instituição, o que evidenciou a descontinuidade política entre as gestões e a falta de compromisso com as políticas públicas.

Constatou-se que as ações políticas implementadas nos últimos oito anos no município de Ilhéus-BA foram insuficientes e não focaram a melhoria na qualidade de vida da população e o acesso ao direito. Em vez disso, valorizaram as práticas de cunho esportivo, na maioria das vezes, com foco no esporte de alto rendimento e na formação de atletas. De acordo com Borges e Tonini ${ }^{31}$, a aplicação de recursos públicos no esporte de alto rendimento, corresponde a uma estratégica de ação do Estado para manutenção de suas prerrogativas institucionais, que variam de acordo com as concepções políticas de cada governo.

A evidência de que o esporte de alto rendimento é o foco, foi verificado na formação do Organograma, na infraestrutura e em alguns trechos dos projetos analisados da Semec. No Projeto Jogos Escolares, ${ }^{32: 3}$ por exemplo, tem como escopo desenvolver:

"[...] as suas atividades com eficiência, através do estímulo a mudança de hábitos e atitudes os quais venham contribuir para o sucesso da interação social. Num segundo momento formar atletas, com vistas ao exercício da cidadania, buscando valores de respeito e disciplina que o Esporte proporciona" (grifo nosso).

Foi perceptível nos relatos dos gestores que o foco da Semec foi o esporte de rendimento, voltado para formação de atletas, o que corrobora com os dados apresentados por Bracht. ${ }^{24}$

Verificou-se em duas entrevistas o pensamento ainda limitado sobre o esporte. Na primeira entrevista foi constatado o entendimento restrito do conceito de esporte, expresso no seguinte trecho da entrevista:

[...] conseguimos fazer alguns torneios de vários esportes, de vários bairros e distritos de Ilhéus, mas poderia ser bem melhor se houvesse uma educação esportiva e educacional do município, que fosse investido mais dessa quantidade enorme de jovens e que Ilhéus poderia ser o fornecedor de craques para o Governo Federal [...] (G1).

Em seguida foi declarado que a participação na política nos campos do esporte e do lazer foi presente no orçamento participativo, com a aprovação do investimento para uma instituição privada, conforme relato do gestor a seguir:

[...] de várias formas, nós tivemos [...] um orçamento do esporte bastante participativo, tanto que nós enviamos esforços no sentido [...] de elevar o Colo Colo a ser um time campeão [ ] [no Campeonato Baiano de Futebol] em 2006. A seleção de Ilhéus foi um apoio irrestrito nosso... escolinha de futebol em bairros, grandes torneios estudantis, torneio interdistrital (G2).

Conexões: revista da Faculdade de Educação Física da UNICAMP, Campinas, v. 11, n. 3, p. 13-35, jul./set. 2013. 
Apesar de a participação política ser um princípio importante para o desenvolvimento de uma gestão pública democrática e intersetorial, conforme descrito por Junqueira, Inojosa e Komatsu, ${ }^{15}$ a participação ficou limitada ao orçamento participativo e ao processo de decisão para o direcionamento de recursos públicos para o esporte de alto rendimento, sobretudo para o Colo Colo de Futebol e Regatas, clube de futebol profissional da cidade, que foi campeão baiano de futebol em 2006.

No Projeto Liga de Esportes ${ }^{33: 4}$ foi verificado um conceito mais amplo de esporte, isto é, buscou-se uma linha esportiva distinta ao propor o seguinte objetivo de desenvolver “[...] no município de Ilhéus o esporte amador, direcionando a prática esportiva coletiva e organizada as suas atividades”. O projeto buscou ainda as mudanças de estilo de vida em prol da qualidade de vida e interação social.

Assim, Ilhéus entende o esporte a partir de uma única dimensão descrita por Tubino, ${ }^{23}$ uma vez que foram perceptíveis as articulações em prol do esporte de rendimento, sobretudo com a aprovação de recursos municipais no orçamento participativo para o Colo Colo de Futebol e Regatas. A aprovação deste investimento na fala do gestor provoca um estranhamento, já que a aprovação de um investimento público para um clube esportivo tem como foco o interesse de poucos cidadãos que se interessam pelo esporte de rendimento.

Os documentos analisados evidenciaram ainda uma mínima articulação das políticas públicas de esporte e de lazer de Ilhéus com a sociedade civil e instâncias governamentais em âmbito estadual. Só a partir do ano de 2007 foi verificada a participação entre setores municipais em três projetos: Jogos Escolares em 2008, que articulou com a Secretaria de Saúde e Departamento de Trânsito de Ilhéus; Esporte para Todos (2008), que articulou com a UESC, Faculdade de Tecnologia e Ciências (FTC), Faculdade Monte Negro e Unime (União Metropolitana de Educação e Cultura); e o Projeto Verão Ilhéus Fitnnes ${ }^{34}$ (2007-2008), que articulou com empresas privadas e patrocinadores para execução do projeto.

No item participação da comunidade, em dois projetos foi possível verificar esta articulação: Projeto Verão Ilhéus Fitnnes ${ }^{34}$ e Projeto Esporte para Todos. ${ }^{35}$ Ambos os projetos desenvolviam atividades esportivas com a comunidade, buscando a integração política e social dos sujeitos. A participação registrada no município de Ilhéus foi Conexões: revista da Faculdade de Educação Física da UNICAMP, Campinas, v. 11, n. 3, p. 13-35, jul./set. 2013. 
superficial e ficou restrita a consulta sobre as ações desenvolvidas, não envolvendo a sociedade civil no processo de participação e decisões políticas.

Em relação à articulação intersetorial, foi realçado que: [...] "havia uma relação de "amizade" com pessoas entre as secretarias, mas na verdade, a prefeitura de Ilhéus na minha época era feita como se fosse uma ditadura e quem mandava era o prefeito" (G1). Também foi declarado que a articulação intersetorial na segunda gestão aconteceu de:

[...] forma regular, mas para contento que regular, porque as instituições públicas e privadas eram necessárias para o bom andamento da secretaria de esporte e nisso nós enviamos esforços também [...], para determinado fim, e apesar de pouco lucrativo, houve grande participação tanto no âmbito institucional como nas políticas públicas e privadas [...] Nós tivemos de várias formas este processo de planejar juntos com a Fundação Cultural (G2).

As entrevistas com os gestores reafirmam a visão limitada acerca da intersetorialidade, compreendida apenas como uma parceria, sendo verificadas apenas algumas relações superficiais, citada pelo G1 na forma de "amizade", e as relações entre instituições públicas e privadas citadas pelo G2.

Os achados correspondentes a intersetorialidade nas políticas públicas de esporte e lazer em Ilhéus corroboram com outros estudos realizados no Brasil. Podemos citar o estudo de $\operatorname{Santos}^{36}$, que investigou as perspectivas intersetorialidade nos setores de esporte e lazer da cidade de Vitória no Espírito Santo, concluindo que a dinâmica intersetorial foi superficial e difusa no processo de elaboração, implementação e avaliação de políticas públicas. Merece destaque também os achados dos estudos de Linhales et al., ${ }^{37}$ que analisaram a gestão pública de esporte e lazer em 13 municípios da Grande Belo Horizonte, enfatizando que a intersetorialidade tem sido compreendida na maioria das vezes como troca de favores entre as secretarias, e, poucos gestores entrevistados apontaram as ações intersetoriais como troca de conhecimentos e experiências, com o objetivo de integrar as ações e colocar o cidadão no centro do processo.

No que diz respeito à articulação intergovernamental foi verificada a mínima articulação. O G1 afirmou que "[...] infelizmente não havia muita relação de "amizade" entre o prefeito e o governador do Estado". Enquanto que o G2 relatou a inexistência de articulação intergovernamental ao afirmar que o município não estava habilitado. Vale ressaltar, que 
não foi constatada a implementação dos programas federais, como o PELC e o Programa Segundo Tempo, mostrando a falta de articulação política.

Esta falta de articulação política e a mínima participação da sociedade civil no processo de gestão pública de Ilhéus se assemelham às experiências descritas em Marcellino, ${ }^{38}$ ao apresentar os resultados das pesquisas em diferentes cidades brasileiras (Florianópolis, São Paulo, Belém, Caxias do Sul e Porto Alegre). Além disso, a intersetorialidade está além da mera parceria, isto é, envolve a articulação entre os três níveis de governo, entre os setores de uma mesma instância, bem como a articulação com o setor privado e a sociedade civil, no processo de planejamento, implementação e avaliação de políticas públicas. Uma ação intersetorial requer um processo de formação dos agentes e distribuição de poder, gerando o conflito e levando tempo para sua adaptação.

O modelo de articulação política que pode servir como suporte para o desenvolvimento das ações políticas no município de Ilhéus foi discutido por Carvalho, ${ }^{39}$ ao afirmar que o processo de formulação de políticas públicas intersetoriais deve envolver a discussão de identificação de diversos atores e dos diferentes interesses que permeiam a luta por inclusão de determinada questão na agenda pública.

Dentre as ações desenvolvidas pela Semec, o Projeto Verão Ilhéus Fitnnes foi o único que planejou as ações de forma intersetorial. Além disso, o projeto corresponde a principal ação política do setor e acontece em todos os anos, envolvendo uma série de modalidades esportivas: Vôlei de Areia, Futebol de Areia, Futevôlei, Esportes Radicais, Duatlôn (Competição dividida em três etapas: corrida, ciclismo e corrida), Dança, Boxe, Jiu-jitsu, Handbeach (Esporte semelhante com o futebol, no entanto, foi jogado com as mãos), dentre outras atividades físicas. O objetivo central do Projeto Verão Ilhéus Fitnnes ${ }^{34: 1}$ foi consolidar o esporte no verão ilheense, para que possa abranger diversas modalidades e viabilizar ações e recursos para fortalecer o esporte: “[...] criando assim o hábito de competições e conseguintemente valorizando o esporte amador na estação do verão, priorizando também os Turistas".

No entanto, este projeto mesmo sendo a maior ação da Semec, enfrenta dificuldades para integração dos setores, em específico com o turismo, uma vez que uma das prioridades do projeto foi atingir os turistas e não foi perceptível a articulação com a Secretaria de Turismo. Foram constatadas apenas articulações com empresas privadas, com o intuito de Conexões: revista da Faculdade de Educação Física da UNICAMP, Campinas, v. 11, n. 3, p. 13-35, jul./set. 2013. 
conseguir o patrocínio. Entre os diferentes atores sociais, só houve participação da população no planejamento por meio das Associações Esportivas. Esta integração com a comunidade foi realizada de forma superficial e muitas vezes, voltava-se apenas para execução de eventos itinerantes, não tendo uma participação efetiva da sociedade civil.

As entrevistas corroboraram com os documentos e apontaram o pouco envolvimento da comunidade na gestão pública nos âmbitos do esporte e do lazer. No entanto, mesmo com esta dificuldade, o G1 afirmou que com "amizade" e interação com a comunidade, foi realizado vários torneios para diversas faixas etárias, sendo articulada com os professores de Educação Física.

O modelo de participação da comunidade no processo político pode ser entendido como uma alternativa operacional dentro das políticas públicas, em especial no campo do lazer, que não pode ficar reduzida a "indústria cultural". No caso de Ilhéus, a ação comunitária não foi presente na política local e o participar ficou restrito a realização de eventos corriqueiros.

Pontua-se que não foi identificado nenhum investimento do poder público voltado para qualificação profissional dos gestores e sociedade civil em prol do desenvolvimento e avaliação das ações intersetoriais. O G1 e o G2 afirmaram que não tiveram nenhum curso científico voltado para os atores sociais, apenas para qualificação e formação de árbitros. Brust, Baggio e Saldanha Filho ${ }^{40}$ assinalam que a qualificação profissional por meio de conferências e/ou eventos deste caráter, permitiu que a comunidade em geral, refletisse sobre a temática do esporte e do lazer, buscando espaço e garantia de investimento por parte do setor público.

Belloni, Magalhães e Souza $^{40}$ defendem que a formação de agentes sociais e o desenvolvimento do conceito e a intersetorialidade são elementos que auxiliam na avaliação. Os indicadores da avaliação são: a) formação continuada dos gestores; b) qualidade e quantidade dos equipamentos; e c) legislação de incentivo. Os indicadores básicos são de fundamental importância para os administradores realizarem o planejamento, execução e avaliação das ações e dos resultados almejados pela política.

Os dados coletados apontaram que os projetos desenvolvidos não seguiam as exigências do modelo proposto por Farah, ${ }^{10}$ e não integravam os processos de planejamento político 
adequadamente. Em uma das entrevistas foi constatada a inexistência do planejamento político em Ilhéus. Um gestor afirmou que "[...] gostaria que houvesse realmente um planejamento na minha cidade" (G1). O gestor detalha que o planejamento em Ilhéus só ocorreu de forma imediata, para suprir as necessidades da população quando se aproxima do período eleitoral, caracterizando assim, em uma política para ganho de votos.

De acordo com o G2 o planejamento ocorria de forma regular, o governo não aprovava as metas dos projetos de esporte no município, tanto na esfera estadual como na esfera federal. O G1 assegurou que Ilhéus necessita realizar um melhoramento no planejamento político e propõe a integração das instituições superiores, câmara de vereadores e prefeito em consonância com as secretarias.

Para finalizar a análise do planejamento da Semec é relevante citar Melo, ${ }^{41}$ uma vez que o autor propõe o exercício de planejamento integrado, que reconheça as diversidades de atividades, de forma a atingir a participação de todos. A programação deve atender a todos os segmentos sociais e levar em conta todas as faixas etárias e gêneros.

\section{CONSIDERAÇÕES FINAIS}

O objetivo da pesquisa foi alcançado, à medida que foi possível compreender e verificar as formas de planejamento e de gestão pública de Ilhéus, bem como o nível de articulações intersetoriais, intergovernamental e participação da sociedade civil. Apesar de fornecer indicativos importantes para o planejamento político da região, devem ser consideradas na pesquisa as seguintes limitações: a pequena quantidade de documentos existentes nas instituições; a constante troca de gestores nas duas gestões; e a resistência dos gestores da segunda gestão em responder as entrevistas.

Os resultados apontaram para a necessidade de integrar a sociedade civil e o setor privado ao planejamento nos setores do esporte e do lazer, em um modelo de cogestão, que aproxima o Estado, o mercado e a sociedade civil. O modelo de participação não deve permanecer apenas em opiniões da comunidade, mas em criar mecanismos para que a sociedade civil participe das decisões e processo de democratização das ações políticas. Verificou-se uma mínima participação da sociedade civil, bem como uma espontaneidade no processo de planejamento da secretaria pesquisada. 
Ficou claro nos dados apresentados que o município considerou o esporte e o lazer como complementos de outras ações políticas, sendo válido destacar a necessidade de ampliarem a abrangência social e o envolvimento dos diversos setores, com o intuito de melhorar a consistência das ações para além do oferecimento da política. Da mesma forma, devem ser previstas ações articuladas e integradas, para que as práticas venham a promover melhorias na qualidade de vida da população, garantia dos direitos, eficiência, eficácia e efetividade social.

Tem-se a expectativa de que as políticas públicas possam contribuir para o desenvolvimento do indivíduo como um todo. Outro ponto importante foi a incipiência de uma estrutura pública administrativa nos setores, que buscasse a qualificação dos gestores para trabalhar de forma integrada com incentivos na sua formação profissional. Por fim, foi evidenciado que todas as secretarias pesquisadas, carecem de programas que contemplem a gestão pública intersetorial, bem como a qualificação e a formação profissional.

\section{REFERÊNCIAS}

${ }^{1}$ CASTEllani FILHO, L. (Org.) . Gestão pública e política de lazer: a formação de agentes sociais. Campinas: Autores Associados, 2007. v. 1. 142p

${ }^{2}$ PAULA, A. P. P. Por uma nova gestão pública. Rio de Janeiro: FGV, 2005.

${ }^{3}$ BOURDIEU, P. Questões de sociologia. Rio de Janeiro: Marco-Zero, 1983. p. 137-153.

${ }^{4}$ ELIAS, N. A génese do desporto: um problema sociológico. In: ELIAS, N.; DUNNING, E. (Org.). A busca da excitação. Lisboa: Difel, 1992. p. 187-221.

${ }^{5}$ ILHÉUS. Câmara Municipal. Lei orgânica do município de Ilhéus. Ilhéus, 2002.

${ }^{6}$ BARDIN, L. Análise de conteúdo. Lisboa, Edições 70, 2009.

${ }^{7}$ HEIDEMANN, F. Do sonho do progresso às políticas de desenvolvimento. In: HEIDEMANN, F; SALM, J. F. (Org.). Políticas públicas e desenvolvimento: bases epistemológicas e modelos de analise. Brasília: Ed. da UnB, 2009 
${ }^{8}$ DI GIOVANnI, G. As estruturas elementares das políticas públicas. Caderno de Pesquisa, Campinas, n. 82, 2009.

${ }^{9}$ PUPPIM DE OLIVEIRA, J. A. Desafios do planejamento em políticas públicas: diferentes visões e práticas. Revista de Administração Pública, Rio de Janeiro, n. 40, p. 273-288, mar./abr. 2006.

${ }^{10}$ FARAH, M. F. S. Parcerias, novos arranjos institucionais e políticas públicas no nível local de governo. Revista de Administração Pública, São Paulo, v. 35, n. 1, p. 119-144, 2001.

${ }^{11}$ ANDRADE, J. V. Gestão em lazer e turismo. Belo Horizonte: Autêntica, 2001.

${ }^{12}$ TENÓRIO, F. G. (Re)visitando o conceito de gestão social. Desenvolvimento em Questão, Ijuí, v. 3, p. 101-124, 2005.

13 Gestão social: uma perspectiva conceitual. RAP, Rio de Janeiro, v. 32, n. 5, p. 7-23, set./out. 1998.

${ }^{14}$ JUNQUEIRA, L. N. P; INOJOSA, R. M.. Desenvolvimento social e intersetorialidade: a cidade solidária. São Paulo: Fundap, 1997.

${ }^{15}$ JUNQUEIRA, L. A. P.; INOJOSA, R. M; KOMATSU, S. Descentralização e intersetorialidade na Gestão Pública Municipal no Brasil: a experiência de Fortaleza. In: PÉREZ, H. O. El tránsito de la cultura burocrática al modelo de la gerencia pública: perspectivas, posibilidades y limitaciones. Caracas: Unesco, 1997. p. 63-124.

${ }^{16}$ BRASIL. Senado Federal. Constituição da República Federativa do Brasil. Brasília, 1988.

${ }^{17}$ BRASIL. Ministério do Esporte. I Conferência Nacional do Esporte: documento final. Brasília, 2004. 
${ }^{1817}$ BRASIL. Ministério do Esporte. II Conferência Nacional do Esporte: caderno de resoluções. Brasília, 2006.

${ }^{19}$ TERRA, A. M et al. As conferências nacionais do esporte: avanços e limites na construção das políticas de Esporte e Lazer. In: CONGRESSO BRASILEIRO DE CIÊNCIAS DO ESPORTE, 16., 2009, Salvador. Anais... Salvador, 2009.

${ }^{20}$ DUMAZEDIER, J. Lazer e cultura popular. São Paulo: Perspectiva, 1973.

${ }^{21}$ MARCELLINO, N. C. Estudos do lazer: uma introdução. 4. ed. Campinas: Autores Associados, 2006. v. 1.100 p.

${ }^{22}$ BELLEFLEUR, M. Le loisir contemporain: essai de philosophie sociale. Québec: Presses de l’Université du Québec, 2002. p. 192.

${ }^{23}$ TUBINO, M. J. G. O Esporte no Brasil, do período colonial aos nossos dias. São Paulo: Ibrasa, 1996.

${ }^{24}$ BRACHT, V. Sociologia crítica do esporte: uma introdução. 2. ed. Ijui: Ed. da Unijuí, 2003. v. 1. 134p .

${ }^{25}$ BONALUME, C. R. Esporte e lazer na intersetorialidade das políticas públicas. In: CONGRESSO BRASILEIRO DE CIÊNCIAS DO ESPORTE, 16., 2009, Salvador. Anais... Salvador: CBCE, 2009.

${ }^{26}$ JUNQUEIRA, L. A. P. A gestão intersetorial das políticas sociais e o terceiro setor. Saúde e Sociedade, São Paulo, v. 13 n.1, p. 25-36, jan./apr. 2004.

${ }^{27}$ BONALUME, C. R. O Paradigma da intersetorialidade nas políticas públicas de esporte e lazer. Licere, Belo Horizonte, v. 14, p. 1-26, 2011.

${ }^{28}$ ILHÉUS. Secretaria Municipal de Esporte e Cidadania. Relatório da primeira gestão da Semec (2001-2004). Semec. Ilhéus, 2005. 
${ }^{29}$ ILHÉUS. Secretaria Municipal de Esporte e Cidadania. Organograma da Semec. Semec. Ilhéus, 2008.

${ }^{30}$ SANTOS, F. C; AMARAL, S. C. F. Sobre lazer e políticas sociais: questões teóricoconceituais. Pensar a Prática, Goiânia, v. 13, p. 1-13, 2010.

${ }^{31}$ BORGES, C. N. F; TONINI, G. T. O Incentivo ao esporte de alto rendimento como política pública: influências recíprocas entre cidade e esporte. Revista Brasileira de Ciências do Esporte, v. 34, p. 281-295, 2012.

${ }^{32}$ ILHÉUS. Secretaria Municipal de Esporte e Cidadania. Projeto Jogos Escolares. Ilhéus, 2008.

${ }^{33}$ ILHÉUS. Secretaria Municipal de Esporte e Cidadania. Projeto Liga de Esportes. Ilhéus, 2008.

${ }^{34}$ ILHÉUS. Secretaria Municipal de Esporte e Cidadania. Projeto Verão Ilhéus Fitnnes. Ilhéus, 2007.

${ }^{35}$ ILHÉUS. Secretaria Municipal de Esporte e Cidadania. Projeto Esporte para Todos. Ilhéus, 2007

${ }^{36}$ SANTOS, M. I. Perspectivas de gestão participativa no setor de esporte e lazer da administração municipal de Vitória-ES. 2013. Dissertação (Mestrado em Educação Física) - Universidade Federal do Espírito Santo, Vitória, Espírito Santo, 2013.

${ }^{37}$ LINHALES, M. A. et al. Esporte e lazer na grande BH: por onde caminham as gestões públicas? In: ISAYAMA; H. F; LINHALES, M. A. (Org.). Avaliação de políticas e políticas de avaliação: questões para o esporte e o lazer. Belo Horizonte: Ed. da UFMG, 2008. v. 1. p. 13-57. 
${ }^{38}$ MARCELlinO, N. C. Políticas públicas setoriais de lazer: o papel das prefeituras. Campinas: Autores Associados, 1996.

${ }^{39}$ CARVAlHO, A. Políticas públicas. Belo Horizonte: Ed. da UFMG, 2002.

${ }^{40}$ BRUST, C.; BAGGIO, I. C.; SALDANHA FILHO, M. F. Repensar a gestão das políticas públicas de esporte e lazer: o caso de Santa Maria/RS. Motrivivência, Florianópolis, ano 18, n. 27, 2006.

40 BELloni, I; MAGAlHÃes, H; SOUZA, L. C. Metodologia de avaliação em políticas públicas: uma experiência em educação profissional. 4. ed. São Paulo: Cortez, 2007.

${ }^{41}$ MELO, V. A. Projetos sociais de esporte e lazer: reflexões, inquietações, sugestões. Quaderns d'Animació i Educació Social, v. 7, p. 8, 2008.

Recebido em: 19 set. 2012 Aceito em: 07 jul. 2013 Contato: Dirceu Santos silva dirceu_09@yahoo.com.br 